\title{
Capital social em rede organizacional: uma análise de suas dimensões explicativas
}

\section{Explanatory dimensions of social capital in networks: a multivariate approach}

\author{
Paulo José Silva ${ }^{1,2}$ \\ Mozar José de Brito ${ }^{3}$ \\ Ana Rosa de Sousa ${ }^{4}$ \\ Valéria da Glória Pereira Brito ${ }^{5}$
}

\begin{abstract}
Resumo: Neste artigo, abordam-se os resultados de uma pesquisa cujo objetivo foi investigar os construtos explicativos do capital social presente na rede organizacional formada por empresas do setor de eletroeletrônicos da cidade de Santa Rita do Sapucaí, MG. Partiu-se do pressuposto de que o referido capital social é constituído por três dimensões analíticas, ou seja, os constructos de natureza estrutural e relacional e aqueles que retratam os benefícios e as restrições relativas à formação desse tipo de capital social. Para validar este modelo explicativo e testar as hipóteses a ele adjacentes, empregou-se o método de pesquisa descritiva ancorado pela Parcial Least Square Path Modeling (PSL-PM). As análises dos resultados obtidos a partir da aplicação da modelagem de equações estruturais evidenciaram que o modelo explicativo proposto tem validade nomológica e estrutural.
\end{abstract}

Palavras-chave: Capital social; Redes organizacionais.

\begin{abstract}
This article discusses the results of a research that aimed to investigate the explanatory constructs of social capital present in an organizational network composed of companies from the electrical and electronics sector in the municipality of Santa Rita do Sapucaí, Minas Gerais state, Brazil. We started from the assumption that the capital present in the network consisted of three analytic dimensions, that is, the constructs of structural and relational nature, and those that portray the benefits and restrictions of this type of social capital. To validate this explanatory model and test the hypotheses surrounding it, we utilized the method of descriptive research anchored by Partial Least Squares Path Modeling (PSL-PM). Analysis of the results obtained from the application of structural equation modeling showed that the proposed explanatory model presents structural and nomological validity.
\end{abstract}

Keywords: Social capital; Organizational networks.

\section{Introdução}

Este artigo faz parte de um projeto de pesquisa financiado pelo Conselho Nacional de Desenvolvimento Científico e Tecnológico (CNPq, Brasil), no qual se enfocou o processo de formação de capital social em uma rede de empresas do setor de eletroeletrônicos e telecomunicações localizadas em Santa Rita do Sapucaí, MG. Este setor apresenta desempenho destacado

no sistema produtivo nacional, tanto do ponto de vista tecnológico como do econômico e do social. Ele produz avanços tecnológicos, emprega milhares de pessoas e contribui para a eficiência de serviços e operações produtivas de outros setores, gerando significativo efeito econômico para o conjunto das economias regionais e nacionais (ABINEE, 2009).

\footnotetext{
${ }^{1}$ Centro Universitário de Formiga - UNIFOR-MG, Rua Dr. Arnaldo Sena, 328, CEP 35570-000, Formiga, MG, Brasil, e-mail: paulojoses@uol.com

${ }^{2}$ Fundação Educacional de Divinópolis - FUNNEDI, Universidade Estadual de Minas Gerais - UEMG, MG 050, Km 109, São José dos Salgados, CEP 35510-000, Carmo do Cajuru, MG, Brasil

${ }^{3}$ Programa de Pós-graduação em Administração, Universidade Federal de Lavras - UFLA, CP 3037, CEP 37200-000, Lavras, MG, Brasil, e-mail: mozarbrito@gmail.com

${ }^{4}$ Centro Universitário de Lavras - UNILAVRAS, Rua Padre José Poggel, 506, Bairro Centenário, CEP 37200-000, Lavras, MG, Brasil, e-mail: arsadm@hotmail.com

${ }_{5}^{5}$ Programa de Pós-graduação em Administração Pública, Universidade Federal de Lavras - UFLA, CP 3037, CEP 37200-000, Lavras, MG, Brasil, e-mail: vgpbrito@dae.ufla.br
} 
Segundo a Associação Brasileira da Indústria Elétrica e Eletrônica (ABINEE), o faturamento das empresas deste setor cresceu, nos últimos três anos, a uma taxa média de $9 \%$ ao ano, alcançando a marca de $4,2 \%$ do PIB, em 2008. Destaca-se também que ele emprega cerca de 161.900 pessoas (engenheiros, técnicos eletrônicos, gestores, operários) e dá origem a uma base tecnológica que viabiliza a aplicação de novas tecnologias de informação e comunicação que, por sua vez, garantem a modernização e a eficiência administrativa e econômica de outros segmentos industriais e de serviços.

Desde o início dos anos de 1990, as empresas do setor eletroeletrônico do Brasil têm enfrentado acirrada concorrência nos mercados local, nacional e internacional. Esse movimento tem se intensificado, exigindo das empresas maior velocidade na incorporação de novas tecnologias, estruturação de uma capacidade financeira e organizacional para realizar investimentos e as parcerias necessárias para conquistar novos mercados e vantagem competitiva. Esse cenário tem exigido a construção de redes de cooperação e práticas de gestão que tenham o mercado consumidor como foco, sejam mais flexíveis e reduzam custos de transação ao longo da cadeia de agregação de valores aos produtos eletroeletrônicos. Ele também está presente no arranjo produtivo de Santa Rita do Sapucaí, MG, que se destaca nacionalmente pela aglomeração de pequenas indústrias de base tecnológica e pela forte integração entre poder público, empresas, instituições de ensino e órgãos de representação empresarial. Estas especificidades deram origem à formação de um arranjo produtivo local que ficou conhecido como Vale da Eletrônica.

A ação coletiva das empresas locais deu origem à formação de uma rede empresarial (Cassiolato \& Lastres, 2003) que tem o apoio de uma sólida estrutura educacional de nível técnico e superior, órgãos públicos e prefeitura, coordenação sindical e apoio da comunidade local. A interação entre esses agentes tem sido apontada, por diversos autores, como sendo responsável pela formação do capital social, uma espécie de ativo relacional que permite a cooperação e facilita a troca de informações entre as organizações constitutivas das redes. Ele pode ser visto como uma credencial social que permite que pessoas, grupos ou organizações tenham acesso aos recursos estratégicos presentes nas redes, reforçando as suas identidades e o reconhecimento social (Lin, 1999).

Neste trabalho, partiu-se do pressuposto de que o capital social presente na rede formada pelas organizações localizadas no Vale da Eletrônica deve ser visto como um fenômeno constituído por uma dimensão socioestrutural e outra relacional, que dão origem a múltiplos benefícios coletivos (obtenção de novos conhecimentos e de vantagem competitiva, acesso a informações de mercado, construção de uma visão de negócios compartilhados) e depende da cooperação e da confiança que marcam as relações entre as empresas constitutivas da rede estudada (Anand et al., 2002; Leana \& Van Buren, 1999; Vidal, 2004). Diante do exposto, foram levantadas as seguintes questões de pesquisa: Quais são os construtos que explicam o capital social presente em uma rede organizacional localizada em Santa Rita do Sapucaí? Qual a intensidade e a natureza das relações entre os referidos construtos? Para responder a essas perguntas, desenvolveu-se este artigo, com o objetivo de investigar os construtos explicativos do capital social presente na rede organizacional formada por empresas do setor de eletroeletrônicos da cidade de Santa Rita do Sapucaí, MG. Mais especificamente, procurou-se: a) propor um modelo explicativo do capital social construído pelas organizações constitutivas da referida rede; b) identificar a natureza e a intensidade das relações entre os construtos propostos para o modelo explicativo; e c) verificar a validade do modelo explicativo do capital social.

Este artigo está estruturado em seis seções. $\mathrm{Na}$ primeira, apresentam-se a introdução e os objetivos do trabalho. Na segunda, destaca-se a fundamentação teórica que serviu de referência para a análise dos resultados. Na terceira, abordam-se os procedimentos metodológicos empregados na pesquisa; na quarta, as análises e a discussão dos resultados obtidos; e na quinta, as considerações finais. Finalmente, na sexta seção, encontram-se as referências bibliográficas utilizadas neste trabalho.

\section{Capital social: gênese e fundamentos teóricos}

A produção científica sobre capital social teve crescimento destacado recentemente e esse fenômeno tem sido investigado sob diferentes perspectivas de análise. Neste tópico, o objetivo é resgatar a gênese do capital social e apresentar as bases teóricas necessárias à formulação do modelo explicativo do capital social presente na rede em análise.

\subsection{A gênese do conceito de capital social}

A revisão de literatura realizada para efeitos deste trabalho indica que a formulação de conceitos de capital social está atrelada aos diferentes enfoques teóricos discutidos por Bourdieu (1979), Coleman (1988) e Putnam (2000). O primeiro autor define o capital social como sendo uma propriedade dos atores, como relações sociais que permitem que indivíduos ou grupos obtenham recursos ou reconhecimento. Coleman (1988), por sua vez, o concebe como um conjunto de elementos de uma dada estrutura social, que possibilita que os atores alcancem seus objetivos. Enquanto o primeiro volta a sua análise sob a ótica do 
agente, o segundo centra suas reflexões na estrutura. Por sua vez, Putnam (2000) define o capital social como característica da organização social que contribui para o aumento da sua eficiência, facilitando a coordenação das ações coletivas. A confiança, a cooperação e as redes são elementos centrais que garantem a eficiência das organizações, das instituições, do Estado e da sociedade (Durston, 2002; Furlanetto, 2008).

Tais concepções clássicas deram origem a diferentes explicações sobre o capital social (Tsai \& Ghoshal, 1998; Koka \& Prescott, 2002; Wíden-Wulff \& Ginman, 2004; Bjørnskov, 2006; Fidrmuc \& Gërxhani, 2008; Agndal et al., 2008; Brunie, 2009; Ahlerup et al., 2009). Esta pluralidade teórico-metodológica decorre da adoção de diversas matrizes epistemológicas que orientam a produção do conhecimento acerca da noção de capital social (Brunie, 2009). Para o autor, esse fenômeno social tem sido abordado sob três prismas epistemológicos, que são: enfoque relacional, coletivo e o generalizado. Neste trabalho, adotou-se o primeiro enfoque, em que o capital social tem sido definido como sendo a capacidade que os atores têm de mobilizar recursos estratégicos por meio dos seus contatos sociais. Essa perspectiva de análise enfoca o capital social como algo desenvolvido e mantido por meio dos contatos entre os atores de uma determinada rede formada por pessoas, grupos ou organizações, bem como reconhece a relevância das redes de contatos como mecanismo de acesso aos recursos, em qualidade e quantidade desejada pelos atores (Anand \& Khanna, 2000; Koka \& Prescott, 2002; Oliver, 2001; Stuart, 2000; Borgatti \& Cross, 2003; Lin, 2008).

\subsection{As dimensões do capital social sob a ótica dos estudos organizacionais}

O capital social tem sido abordado pelos estudos organizacionais como um construto multidimensional que incorpora duas dimensões analíticas que são: a) a estrutural - composta pela rede de contatos e sua natureza (densidade; centralidade, intermediação, proximidade, entre outros aspectos morfológicos) e b) a relacional - constituída por confiança, cooperação, normas e compromissos e outros comportamentos produzidos a partir dos laços estabelecidos entre os atores (De Wever et al., 2005; Nahapiet \& Ghoshal, 1998; Galunic \& Moran, 2000; Batjargal, 2003). Para explicar a dimensão estrutural do capital social, os analistas organizacionais têm recorrido, entre outros autores, à abordagem estruturalista de Granovetter (1994). Este autor partiu do pressuposto de que toda ação econômica dos atores será sempre marcada pelo conteúdo e pela estrutura das redes e dos vínculos sociais que lhes dão sustentação ao longo do tempo (Granovetter, 1973, 1985, 1990; Granovetter \& Swedberg, 1992). Ao transpor esta tese do embeddedness para os grupos de empresa, Granovetter (1994) apontou os limites da teoria microeconômica e defendeu que o mercado não se constitui de organizações isoladas, mas de aglomerados delas, formando uma estrutura em rede que contribui para a formação do capital social. Portanto, a emergência do capital social estaria enraizada na constituição das redes interorganizacionais.

Provan et al. (2007) concebem as redes organizacionais como sendo um todo que abriga um grupo de três ou mais organizações que estão conectadas entre si por meio de um processo social que facilita o alcance de objetivos comuns. Estes autores afirmam que as redes devem ser formalmente estabelecidas e governadas, orientadas para objetivos de modo a priorizar a horizontalidade das relações e garantir que as organizações (que dela fazem parte) tenham autonomia para efetuar as suas próprias operações. Machado-da-Silva \& Coser (2006) afirmam que a rede, na atualidade, seria a imagem que mais se aproxima do desenho das relações interorganizacionais. Essa aproximação conceitual tem permitido que os pesquisadores da área de administração recorram a alguns dos fundamentos teórico-metodológicos da teoria Social Network Analysis para produzir explicações sobre a dimensão estrutural do capital social. A referida teoria tem gerado métodos e técnicas que permitem a representação das estruturas das redes sociais ou organizacionais (Wasserman \& Faust, 1994; Molina, 2001). Para estes atores, esta abordagem permite a descrição detalhada das propriedades da rede, tais como centralidade, intermediação e proximidade entre atores da rede.

Para Provan et al. (2007), as explicações sobre a dimensão estrutural procuram, essencialmente, evidenciar como o envolvimento de uma organização ou ator na rede afeta suas ações e resultados. A dimensão estrutural das redes influencia a forma pela qual as informações são trocadas entre as organizações, a densidade dos laços tende a aumentar ao longo do tempo e a centralização pode facilitar a integração e a coordenação da rede (Kaasa, 2009; Batt, 2008; Agndal et al., 2008; Sabatini, 2008; De Wever et al., 2005; Batjargal, 2003; Adler \& Kwon, 2002). A análise da dimensão estrutural do capital social permite que o pesquisador compreenda como e quando uma organização identifica e adquire recursos estratégicos, bem como informa como os valores são agregados à sua ação (Tsai \& Ghoshal, 1998). Os resultados e os benefícios da rede estariam associados à posição ocupada pelo ator na rede ou ao controle de recursos estratégicos. Assim, a obtenção de benefícios advindos da ação coletiva depende da tipologia local da rede e dos laços que são formados como mecanismo de alavancagem estrutural (Borgatti \& Foster, 2003). 
A dimensão estrutural do capital social poderá sofrer influência de diversos fatores, tais como forma de governança, ação do poder local e contexto institucional, entre outros. Para Provan et al. (2007), a forma de governança também causa impacto nos resultados da ação em rede. Para estes autores, é muito comum encontrar três formas de governança, a saber: a) governança compartilhada baseada no compromisso assumido e na tomada de decisão estratégica e operacional coletiva; portanto, não há uma estrutura formal e única de coordenação; ela é exercida de forma cooperativa e o controle pode ser dar por meio de mecanismos contratuais ou informais; b) governança exercida por organização de ligação que permite a participação de todos os membros da rede, mas a coordenação é exercida por uma organização mais poderosa que tem legitimidade social e recursos suficientes para influenciar a tomada de decisão; esse tipo de governança é comum nas redes verticalizadas inspiradas nas grandes organizações do setor automobilístico; e c) governança representativa exercida por uma organização em nome de todas; esta organização conta com a participação e o controle dos membros da rede, tendo como tarefa básica a liderança e a coordenação da ação coletiva.

A noção de governança implica também a construção de uma interface entre os organismos e instituições locais que priorize os fins produtivos e a regulação social necessários à formação do capital social. Para Muls (2008), o capital social deve ser visto como um fundamento sobre o qual se instauram as formas de manifestação autônoma que, por sua vez, se expressam por meio da construção das redes. As formas assumidas pelo capital social em um determinado espaço social ou território, segundo o autor, são a síntese da reação de forças heterônomas desse local que sobre ele se impõem. Para Muls (2008), a formação do capital social teria como ponto de partida a institucionalização de relações sinérgicas entre os organismos, as instituições locais e as redes de organizações, cujas atuações estejam interessadas na produção de forma produtiva socialmente regulada. Os organismos locais teriam a responsabilidade de atuar no sentido de criar coletivamente um ambiente institucional necessário ao desenvolvimento do capital social, a exemplo da definição de políticas públicas de desenvolvimento local, regras ou normas jurídicas que estimulassem a ação coletiva e o fortalecimento da democracia local. A construção desse ambiente institucional parece ser um elemento essencial para a construção da dimensão relacional do capital social.

Essa dimensão também foi denominada, por Batjargal (2003), de embeddedness relacional, cuja origem está vinculada à confiança e à cooperação construída entre os atores da rede, ao longo da história de suas interações. O conceito de confiança tem contribuído para o desenvolvimento de conceitos transversais à ciência administrativa, que podem explicar, em parte, a complexidade da interação entre as organizações e a forma pela qual o capital social dela derivado encontra-se ancorado nas estruturas sociais (Brunie, 2009; Kaasa, 2009; Chow \& Chan, 2008; Gulati \& Nickerson, 2008; Houghton et al., 2009; Theingi et al., 2008; Batt, 2008; Leana \& Pil, 2006; Sorama et al., 2004; Smith \& Lohrke, 2008; Burt, 2001; Adler \& Kwon, 2002). Trata-se de um fenômeno complexo que confere às relações entre organizações um caráter relacional, possibilitando a cooperação, a troca de experiências, a fidelidade, o uso compartilhado de recursos e a comunicação, entre outros aspectos relacionais que são determinantes na construção da dinâmica e integração social da rede (Goel et al., 2005). Nos estudos sobre organizações, a confiança tem sido abordada como um mecanismo de redução dos riscos relativos às relações de troca, à melhoria do processo de comunicação e ao acesso a novas tecnologias e conhecimentos que são compartilhados entre organizações.

Para Gulati \& Nickerson (2008), este construto explica, em parte, as relações interorganizacionais, portanto, a dimensão relacional do capital social (De Wever et al., 2005). A confiança tem sido apontada ora como antecedente, ora como consequência do capital social, ou seja, o capital social gera confiança que, por sua vez, gera capital social. Nesta ótica, a confiança seria resultado da ação coletiva bem sucedida. De um lado, a confiança implica respeito mútuo e reciprocidade e, por outro, ela sugere certo grau de vulnerabilidade e risco (Gulati \& Nickerson, 2008; Björk \& Virtanen, 2005). Ao refletirem sobre a noção de confiança, Lyons \& Mehta (1997) destacam as noções de "confiança socialmente orientada" e "confiança autointeressada". A primeira tem fortes vínculos com o passado (backward-looking) das relações, sendo considerada produto social, cuja institucionalização está atrelada ao contexto sociopolítico. A "confiança autointeressada" teria um caráter instrumental por resultar da interação entre agentes que calculam e avaliam permanentemente os custos, os benefícios e os riscos relativos ao ato de confiar ou não em outro agente. Essas duas categorias não são excludentes entre si. Elas podem, em determinadas circunstâncias, se complementar, dando origem a comportamentos socialmente orientados como aqueles autointeressados inerentes à cooperação entre as organizações.

A cooperação refere-se ao desenvolvimento de ações de natureza coletiva marcadas pela reciprocidade entre as organizações constitutivas da rede organizacional. A cooperação oferece a estes atores uma espécie de seguridade social, no momento em que ele precisa. Trata-se de comportamento simétrico referenciado por expectativas de ajuda mútua e reciprocidade, uma forma de alavancagem do capital social (Onyeiwu \& Jones, 2003). Para os autores, a ausência desse tipo de 
comportamento pode gerar desequilíbrios nas relações de mercado. Essa modalidade de comportamento coletivo requer um longo esforço organizacional, pois as organizações não partilham objetivos, recursos, conhecimentos e decisões de forma imediata. A cooperação depende da construção prévia de laços duradouros (Lima et al., 2006) e da confiança, da formulação de objetivos comuns; do compartilhamento de crenças e valores; da capacidade de negociação e de mediação de conflitos de interesses e da redução dos comportamentos oportunistas, além da abertura dos canais de comunicação e da habilidade e da predisposição para o desenvolvimento de comportamentos cooperativos (Pesämaa \& Hair, 2007; Pesämaa et al., 2007). Para Coser (2003), a cooperação consiste na colaboração entre as organizações da rede para atingir objetivos comuns, que dificilmente seriam alcançados por uma organização isoladamente. Esse aspecto da dimensão relacional do capital social pressupõe a construção de relações ou laços diretos ou indiretos que produzem benefícios e riscos socioeconômicos para as organizações que interagem entre si.

\subsection{Benefícios, motivações e riscos associados ao capital social}

A formação do capital social tem sido motivada muito mais por compromissos normativos do que por orientações instrumentais. A natureza e as especificidades das normas compartilhadas e a confiança construída a partir das redes articuladas entre as organizações podem ser vistas como as principais fontes do capital social. De Wever et al. (2005) reconhecem tanto a dimensão relacional como a dimensão estrutural para defender a tese de que são mecanismos de acesso aos recursos estratégicos presentes nas redes interorganizacionais. Geralmente, as redes são consideradas bem sucedidas quando elas permitem a aquisição desse tipo de recurso, cuja exploração pode gerar vantagens competitivas e agregação de valores para os seus membros. Caso contrário, ela não poderá ser considerada como efetiva na formação do capital social. A efetividade da ação coletiva depende também da configuração da rede, da natureza das interações, da confiança e da cooperação. Essas dimensões do capital social, segundo estes autores, exercem forte influência na melhoria do desempenho, na troca de informações e conhecimentos, no compartilhamento de recursos estratégicos, na inovação e na inserção mercadológica das organizações que atuam em rede (Agndal et al., 2008; Chetty \& Agndala, 2007; Anand et al., 2002). Chow \& Chan (2008) estudaram a relevância do capital social para o acesso ao conhecimento e afirmam que sua dimensão relacional afeta a forma pela qual o conhecimento tem sido compartilhado pelas organizações. A transferência do conhecimento depende das relações de confiança e da cooperação, da intensidade dos laços entre as organizações, da definição clara de objetivos e mecanismos de produção e transferência de conhecimentos entre os parceiros que estão inseridos em uma determinada rede ou outra estrutura social (Houghton et al., 2009).

Leana \& Van Buren (1999) também assinalam que o capital social pode trazer outros benefícios para as organizações em rede. Entre eles, os autores destacam: a) corroborar o comprometimento individual para o bem coletivo; b) facilitar maior flexibilidade no trabalho organizacional; c) servir como um mecanismo para administrar ação coletiva; e d) facilitar o desenvolvimento de capital intelectual na firma. Além disso, o capital social permite que as organizações tenham informações estratégicas e necessárias ao alcance dos seus objetivos e propósitos. Para Adler \& Kwon (2002), o acesso à informação seria o benefício básico do capital social, cujas especificidades produziriam efeitos sinérgicos devido à abertura de novos canais de comunicação, à melhoria da qualidade, à relevância e à precisão da informação que poderá traduzir-se em conhecimento para as organizações ou pessoas que atuam em rede.

A dimensão relacional do capital social e o conjunto de recursos nele imbricado afetam de forma favorável o desempenho de pessoas ou organizações que atuam em parceria (Batjargal, 2003). Por outro lado, a dimensão estrutural, em determinados casos, não afeta diretamente o desempenho das organizações em rede. Para este autor, a capacidade de negociar e mobilizar os recursos físicos e simbólicos, a qualidade dos contatos ou laços e a obtenção de novos conhecimentos e informações têm maior impacto quando comparadas aos elementos da dimensão estrutural do capital. Em síntese, o capital social aumenta o potencial de adaptação, aprendizagem, criatividade e habilidade das organizações em buscar novas oportunidades. Trata-se de um efeito sinérgico que interfere no desempenho da rede. Esse desempenho depende da construção do capital social, ou seja, os resultados da ação coletiva (qualidade, eficácia e eficiência, velocidade, flexibilidade e inovação) serão alcançados na hipótese da existência do capital social (Vale et al., 2006).

A despeito desses resultados positivos, o capital social também pode gerar riscos e resultados negativos. Para Portes (1998), se, por um lado, o capital social permite a troca de informação e fortalece a confiança e a cooperação, por outro, ele poderá reduzir a eficiência da ação coletiva, dada a intensificação dos conflitos de interesses e as disputas de poder entre os atores da rede. Para o caso brasileiro, deve-se acrescentar às considerações do autor a possibilidade de o processo de formação do capital social estar permeado por patrimonialismo, personalismo, clientelismo e paternalismo, entre traços marcantes da cultura brasileira. Essa bricolagem poderá contribuir, 
dependendo das formas de regulação, para a produção de externalidades negativas, a exemplo da produção de relações assimétricas entre as organizações de uma rede, da geração de "canibalismo" entre elas e desigualdades quanto ao acesso de informações e recursos estratégicos. Esses efeitos negativos do capital social podem produzir comportamentos coletivos marcados pela desconfiança e pela ausência de cooperação, reduzindo a probabilidade de acesso a recursos estratégicos (De Wever et al., 2005).

A formação de laços fortes poderá também contribuir para a institucionalização de feudos entre os atores e para a construção de uma visão fragmentada que acaba contribuindo para a redução dos benefícios do capital social (Adler \& Kwon, 2002). Para estes autores, as redes podem promover o desenvolvimento de comportamentos não éticos que podem produzir efeitos negativos sobre a formação, a manutenção e a distribuição do capital social. Esses comportamentos acabam determinando a qualidade das relações entre as empresas pertencentes a uma rede que, por sua vez, intensifica a desconfiança que, muitas vezes, se encontra em estado latente, gerando diversas barreiras à transferência de recursos e agregação de valores nas relações interorganizacionais. Essa sistematização teórica serviu de referência para a formulação do modelo explicativo do capital social retratado na Figura 1.

\section{Procedimentos metodológicos}

Na realização da pesquisa que deu origem este artigo, optou-se por realizar uma pesquisa descritiva de natureza quantitativa (Marconi \& Lakatos, 2003) que fosse capaz de produzir novos conhecimentos acerca das relações estabelecidas entre as empresas localizadas no município de Santa Rita do Sapucaí. Esta cidade foi escolhida por abrigar uma rede de empresas que atuam no setor de eletroeletrônicos e telecomunicações.

O modelo de pesquisa (Figura 1), concebido e fundamentado na teoria do capital social, foi estruturado por três dimensões analíticas constituídas por diversos construtos.

A primeira dimensão incorporou constructos que medem a dimensão estrutural que dá sustentação ao capital social, ou seja, estrutura da rede, ambiente institucional e coordenação da rede. A dimensão relacional abriga os construtos cooperação e confiança, que dão sustentação às relações entre os atores (organizações) membros da rede. A terceira dimensão comporta os construtos relacionados aos benefícios e às restrições associados ao capital social. $\mathrm{O}$ referido modelo de pesquisa hipotetizado agrega o conjunto de relações de dependência que serão testados empiricamente à luz da fundamentação teórica sobre o capital social em redes empresariais. Essas relações de dependência foram representadas graficamente por diagrama de caminhos estruturais (Hair et al., 2005, p. 469) e descritas nos termos que se seguem.

O primeiro grupo de proposições abriga sete hipóteses que evidenciam as relações de dependência entre os construtos (variáveis latentes) da dimensão estrutural e da dimensão relacional do capital social construído na rede de empresas estudada, ou seja: H1: a estrutura da rede está relacionada e impacta positivamente a confiança; $\mathbf{H 2}$ : a estrutura da rede está relacionada e impacta positivamente a cooperação; H3: o ambiente institucional está relacionado e impacta positivamente a confiança; $\mathbf{H 4}$ : o ambiente

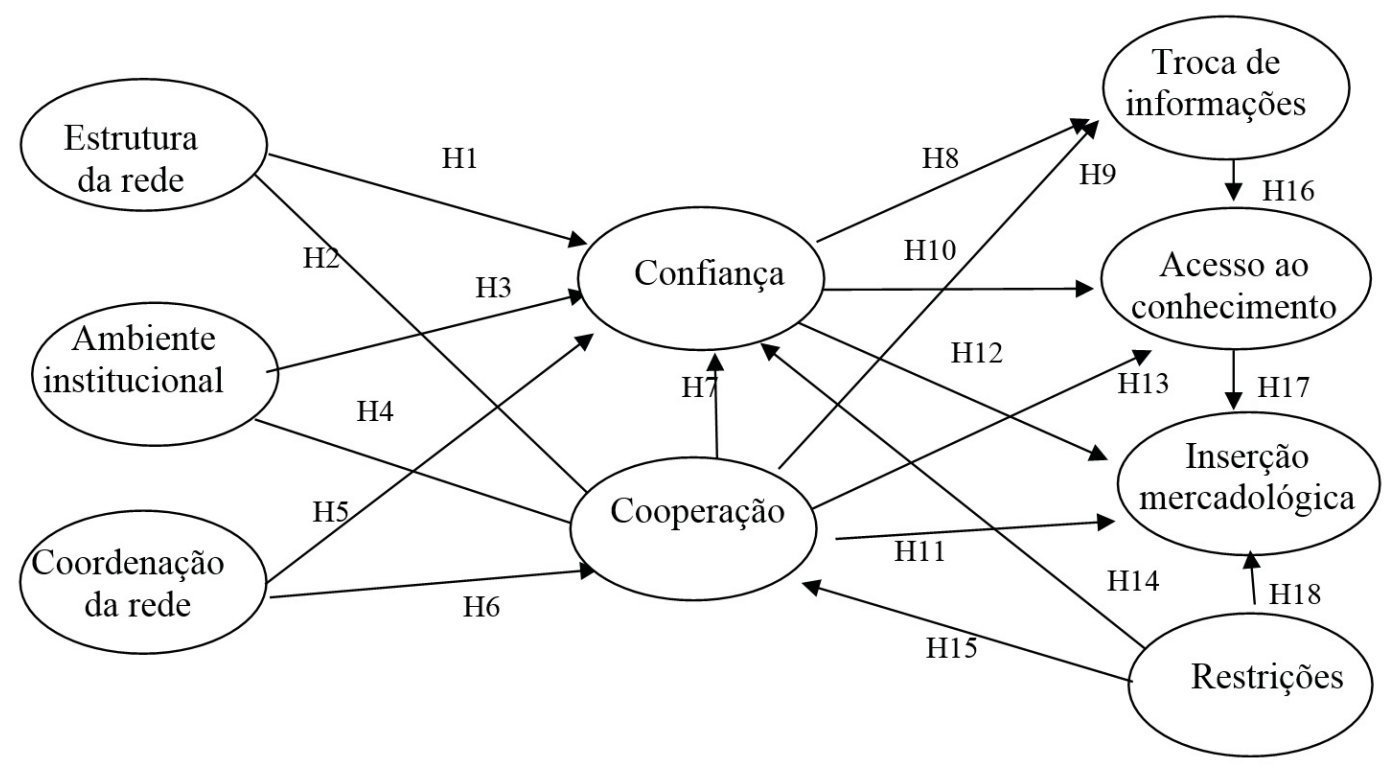

Figura 1. Diagrama de caminhos do modelo explicativo proposto para o capital social. 
institucional está relacionado e impacta positivamente a cooperação; H5: a coordenação da rede exercida pelo sindicato empresarial está relacionada e impacta positivamente a confiança; H6: a coordenação da rede exercida pelo sindicato empresarial está relacionada e impacta positivamente a cooperação; H7: a cooperação está associada e impacta positivamente a confiança.

O segundo grupo de proposições teóricas abriga onze hipóteses que evidenciam as relações de dependência entre os construtos da dimensão relacional e os benefícios e elementos restritivos do capital social, ou seja: H8: a confiança está associada e impacta positivamente ao acesso às informações; H9: a cooperação entre as empresas está associada e impacta positivamente a troca de informações; H10: a confiança está associada e impacta positivamente ao acesso a novos conhecimentos e inovações; H11: a cooperação está associada e impacta positivamente a inserção mercadológica das empresas; H12: a confiança está associada e impacta positivamente a inserção mercadológica das empresas; H13: a cooperação está associada e impacta positivamente a obtenção de novos conhecimentos e inovações; H14: os elementos restritivos à formação do capital social estão associados e impactam negativamente a confiança; H15: os elementos restritivos à formação do capital social estão associados e impactam negativamente a cooperação; H16: a troca de informações está associada à obtenção de novos conhecimentos e inovações; H17: o acesso a novos conhecimentos e inovações está associado e impacta positivamente a inserção mercadológica das empresas integrantes da rede; H18: os elementos restritivos à formação do capital social estão associados e impactam negativamente a inserção mercadológica.

A verificação das relações de dependência entre os construtos teóricos do referido modelo exigiu que a pesquisa de campo fosse realizada em duas fases que se complementam: uma exploratória e outra descritiva. Na fase exploratória, realizou-se extensa revisão de literatura sobre capital social e redes de empresas. Posteriormente, realizaram-se três visitas técnicas ao município de Santa Rita do Sapucaí. Na oportunidade, foram entrevistados cinco empresários, um coordenador da incubadora vinculada ao Instituto Nacional de Telecomunicações, um coordenador da incubadora municipal, um secretário de governo local e um membro do sindicato empresarial, todos indicados pelo sindicato. Nesta fase da pesquisa, o objetivo era explorar aspectos do contexto social e das relações estabelecidas entre as empresas, incluindo aqueles relacionados ao papel desempenhado por instituições de ensino, incubadoras de empresas, governo local e sindicato empresarial. Todas as entrevistas foram registradas em um caderno de campo. Destaca-se que também foi realizada uma pesquisa documental, que envolveu a triagem e a sistematização do acervo local (livros, teses, dissertações) acerca da história da cidade de Santa Rita do Sapucaí e de elementos historiográficos a respeito da criação do Vale da Eletrônica.

Na segunda fase da pesquisa, realizou-se uma pesquisa do tipo survey, que envolveu 115 empresas filiadas ao Sindicato das Indústrias de Aparelhos Elétricos, Eletrônicos e Similares do Vale da Eletrônica (SINDVEL). Deste total, 85 empresas integrantes da rede estudada retornaram os questionários preenchidos por seus dirigentes, tendo 3 deles sido descartados por falta de preenchimento. Portanto, obteve-se uma taxa de retorno de $71,30 \%$, referente aos 82 questionários considerados válidos. Na realização do survey, empregou-se o questionário estruturado, por julgar que esse instrumento permitiria o levantamento dos dados necessários aos testes das hipóteses acima mencionadas. Esse questionário continha questões que permitiram o levantamento de informações relevantes para a caracterização da rede e das empresas que a constituem, a natureza das relações entre elas e a percepção dos gestores em torno da formação do capital social. Os constructos do modelo explicativo do capital social hipotetizado foram mensurados por meio de uma escala de concordância de 5 pontos balanceada, em que os respondentes expressavam a sua percepção acerca de cada um deles, exceto o construto denominado por estrutura da rede. A mensuração desse constructo foi realizada por meio do grau de centralidade, proximidade e intermediação de cada uma das empresas integrantes da rede.

$\mathrm{Na}$ análise dos dados levantados a partir da aplicação do questionário, empregou-se a abordagem denominada de Parcial Least Square Path Modeling (PSL-PM). A escolha da referida abordagem se justifica por ela apresentar as seguintes especificidades: a) maior flexibilidade em termos do tamanho da amostra e da distribuição dos dados; b) permite a verificação da unidimensionalidade de fatores dos blocos de variáveis; c) aborda as variáveis latentes como combinações lineares das variáveis manifestas; e d) estima variáveis latentes como componentes, incorporando outras técnicas de análise multivariada - correlação canônica, análise fatorial e caminho estrutural (Dias, 2007; Maestro, 2004; Tenennhaus et al., 2005; Tenennhaus \& Hanafi, 2007; Wold, 1985).

A aplicação dessa abordagem na análise dos resultados da pesquisa seguiu um rigoroso protocolo de análise que envolveu: a) análise de dados ausentes e da presença de outliers; b) verificação dos pressupostos de linearidade e normalidade da distribuição dos dados; c) aplicação computadorizada da abordagem PSL-PM com base no algoritmo definido a partir do modelo teórico formulado; e d) verificação da validade do modelo e teste de suas hipóteses. Para tanto, aplicaram-se os recursos computacionais ofertados pelo Software Excel XLSTAT PRO 2009 (versão 
registrada) (XLSTAT, 2009). Para verificar a unidimensionalidade dos blocos ou componentes, empregaram-se as medidas Alfa de Cronbach e Rho de Dillon-Goldstein e o valor de eigenvalue da matriz de correlação dos blocos.

Na estimação do modelo estrutural, aplicou-se a técnica de regressão dos quadrados mínimos parciais (PLS) conjugada com a aplicação do processo de reamostragem de Bootstrap. Para verificar a sua validade estrutural, empregou-se o critério de ajuste global (GoF), proposto por Amato et al. (2004) e, para testar as hipóteses e verificar os impactos dos construtos, foram utilizados, respectivamente, os coeficientes de regressão $\left(\mathrm{R}^{2}\right.$ e $\mathrm{R}^{2}$ de Bootstrap ajustado) e os coeficientes parciais ( $($ ) de regressão. Todos os resultados foram analisados considerando o nível de significância estatística de 5\% (p<5), ou seja, com um grau de confiança de $95 \%$. No próximo tópico os resultados são discutidos e analisados.

\section{Capital social em rede: validação do modelo explicativo}

Neste tópico, são apresentados e discutidos os resultados obtidos por meio da modelagem PSL-PM, cujos pressupostos serviram de referência para propor, estimar e validar o modelo explicativo das relações entre os construtos constitutivos do capital social formado a partir das relações estabelecidas entre as empresas. Para efeitos da mensuração e validação do modelo explicativo proposto para este trabalho, partiu-se de dois pressupostos básicos. O primeiro diz respeito à existência de relações causais entre construtos teóricos explicativos do capital social. O segundo refere-se ao pressuposto de que as referidas relações são lineares, portanto, passíveis de serem mensuradas e testadas por meio da aplicação da modelagem de equações estruturais. Na especificação do modelo de mensuração, os construtos estrutura da rede, ambiente institucional, coordenação e restrições foram considerados exógenos (variáveis independentes) e, por sua vez, os construtos cooperação, confiança, acesso a informações, obtenção de conhecimento e inserção mercadológica foram considerados endógenos (variáveis dependentes).

Entre os diversos procedimentos de análise da qualidade do ajuste do modelo de mensuração propostos, destaca-se a análise da confiabilidade e da unidimensionalidade das escalas de mensuração empregadas para o levantamento dos dados empíricos junto às organizações constitutivas da rede interorganizacional estudada. Para Hair et al. (2005), a unidimensionalidade tem sido considerada uma suposição inerente ao cálculo da confiabilidade e sua demonstração ocorre quando as variáveis refletivas de um construto se ajustam por meio da análise fatorial a um só fator. Assim, a confiabilidade seria uma medida de consistência interna das variáveis manifestas que descrevem o grau em que são indicativas do construto latente. Neste trabalho, foram adotadas duas medidas de confiabilidade, o Alfa de Cronbach e Coeficiente Rho de Dillon-Goldstein, tendo esta última sido apontada como uma medida mais rigorosa e confiável, quando comparada à primeira (Chin, 1998). Todos os construtos apresentaram Alpha de Cronbach maior que 0,60, ponto de corte sugerido por Hair et al. (2005) e Rho de D.G. maior que 0,7 (Chin, 1998).

A análise das evidências estatísticas apresentadas na Tabela 1 indica que a escala de mensuração empregada para estimar os construtos do modelo explicativo do capital social apresenta consistência e validade. Em outras palavras, as variáveis manifestas refletem, de forma consistente e válida, os construtos constitutivos do modelo explicativo, indicando que as medidas empregadas apresentaram índice de elevada consistência. Esse critério avalia se a variável manifesta, ou indicador, está realmente medindo aquilo que deve ser medido, isto é, o conceito pretendido (Netemeyer et al., 2003). Portanto, pode-se afirmar que a escala de mensuração adotada de fato apreendeu a percepção dos respondentes da pesquisa sobre os construtos relativos a cada uma das dimensões

Tabela 1. Confiabilidade dos construtos do modelo.

\begin{tabular}{lccccc}
\hline \multicolumn{1}{c}{ Variável latente } & $\begin{array}{c}\mathbf{N}^{\mathbf{0}} \text { de variáveis } \\
\text { manifestas }\end{array}$ & $\begin{array}{c}\text { Alfa de } \\
\text { Cronbach }\end{array}$ & $\begin{array}{c}\text { Rho de D.G. } \\
\text { (ACP) }\end{array}$ & Autovalores & $\mathbf{Q}^{\mathbf{2}}$ \\
\hline Estrutura da rede & 3 & & & 2,035 & 0,014 \\
Ambiente institucional & 4 & 0,745 & 0,840 & 2,275 & 0,211 \\
Coordenação da rede & 3 & 0,859 & 0,914 & 2,342 & 0,356 \\
Restrições ao capital social & 4 & 0,715 & 0,824 & 2,228 & 0,456 \\
Cooperação & 4 & 0,670 & 0,804 & 2,047 & 0,583 \\
Confiança & 5 & 0,815 & 0,871 & 2,882 & 0,426 \\
Acesso a informações & 3 & 0,726 & 0,846 & 1,940 & 0,418 \\
Acesso ao conhecimento & 4 & 0,669 & 0,801 & 2,014 & 0,443 \\
Inserção mercadológica & 4 & 0,704 & 0,818 & 2,125 & 0,529 \\
\hline
\end{tabular}


(estrutural e relacional) e aos benefícios do capital social.

As análises até aqui realizadas dizem respeito à adequação e à validade da escala de mensuração empregada para medir cada uma das variáveis manifestas. Portanto, tendo a validade dessas medidas reconhecidas, passa-se a abordar a validação do modelo de mensuração formulado. $O$ procedimento de análise adotado na avaliação da qualidade do ajuste do modelo de mensuração proposto foi a estatística $\mathbf{Q}^{2}$, cujo valor expressa a qualidade do ajuste entre os construtos ou variáveis latentes e suas respectivas variáveis manifestas. A estatística $\mathbf{Q}^{2}$ para cada construto foi calculada pelo software XLSTAT PLSM-Graph, como sendo (1 - erro/valor da observação). Ressalta-se que quanto maior e positivo for o valor de $\mathrm{Q}^{2}$, maior será a qualidade do ajuste das variáveis manifestas ao seu respectivo construto. A análise dos dados evidencia que os valores de $\mathbf{Q}^{2}$ situaram-se entre 0,014 e 0,583 , tendo o construto estrutura da rede apresentado menor valor e o construto cooperação, o maior valor. Em síntese, a análise dos valores de $\mathbf{Q}^{2}$ estimados por meio do processo de reamostragem (bootstrap), associados à interpretação da relevância das variáveis manifestas indica boa qualidade do modelo de mensuração. Ressalta-se que essas considerações representam o primeiro passo analítico que será acrescido da análise do ajuste geral do modelo estrutural.

O ajuste do modelo envolveu a análise da significância dos coeficientes estimados, dos valores críticos e dos erros das estimativas. O modelo explicativo deu origem a cinco equações estruturais que permitiram o teste dos construtos preditivos da cooperação, confiança, acesso a informações, obtenção de conhecimentos e inovações e inserção mercadológica entre as empresas de Santa Rita do Sapucaí. Para cada equação, foram estimados os coeficientes de regressão ( $\mathrm{R}^{2}$ - Bootstrap) e os coeficientes parciais $(\beta)$ de regressão (Path Coefficients), que serviram de referência para o reconhecimento e a validação das hipóteses adjacentes ao modelo explicativo do capital social hipotetizado. A síntese desses resultados pode ser observada por meio da Tabela 2, cuja análise levou em consideração os resultados das equações estruturais ajustadas.

Observou-se, pela análise dos resultados da Tabela 2, que $53,0 \%$ da variância do construto confiança foram explicados pelos construtos estrutura da rede, ambiente institucional, restrições à formação do capital social, coordenação e cooperação. Verificou-se também que esses constructos estão estatisticamente associados e impactaram positivamente as relações de confiança estabelecidas entre as empresas, exceto a estrutura da rede e o ambiente institucional. Por sua vez, o construto restrições está associado, mas impactou negativamente as relações de confiança. A análise dos coeficientes do caminho estrutural (Path Coefficients) confirma as relações de dependência hipotetizadas para confiança entre as empresas que participam da rede estudada, exceto aquelas que previam associação e impacto positivo da estrutura da rede e do ambiente institucional sobre a confiança. Portanto, pode-se afirmar que as hipóteses $\mathrm{H} 1$ e H3 foram rejeitadas, pois os seus Path Coefficients não foram estatisticamente significativos, apresentando uma razão crítica (RC) menor que o valor recomendado de 1,96.

Constatou-se também que a estrutura da rede e o ambiente institucional apresentam baixo potencial explicativo para as relações de confiança construídas entre as empresas participantes da rede de empresas estudadas. Observou-se que os construtos estrutura da rede e ambiente institucional apresentaram RC de 1,581 e 1,712, respectivamente; os construtos coordenação e restrições à formação da cooperação apresentaram RC de 6,84, $(-7,08)$ e 6,78, respectivamente, estando acima de 1,96 recomendado por O'Cass \& Grace (2008). Observou-se, ainda, que esses construtos apresentaram, respectivamente, poder explicativo de 0,$99 ; 1,44$; e 128 . Portanto, pode-se afirmar que esses constructos impactam de forma significativa as relações de confiança estabelecidas entre empresas que integram a rede estudada.

Pela análise dos dados da Tabela 2, verificou-se que $55,8 \%$ da variância do construto cooperação podem ser explicados pelos construtos estrutura da rede, ambiente institucional, coordenação e restrições da ação em rede. Pode-se também observar que todas as hipóteses testadas pela equação estrutural da cooperação foram aceitas, exceto a que pressupunha uma relação estatisticamente entre a estrutura da rede e a cooperação. Portanto, pode-se afirmar que a estrutura da rede objeto de análise apresenta baixo potencial explicativo das relações de cooperação. O coeficiente de caminho ( $\beta$ ) entre esses dois construtos alcançou a marca de 0,117 , apresentando potencial preditivo de 0,409 , cujo valor encontra-se muito abaixo do valor $(0,80)$ recomendado por (Wold, 1995). Verificou-se também que todos os valores da razão crítica (CR) relativos aos construtos da equação estrutural explicativa da cooperação estão acima do valor de 1,96 sugerido por O'Cass \& Grace (2008). Destaca-se que o constructo coordenação apresenta o maior potencial explicativo da cooperação $(1,20)$, seguido dos construtos ambiente institucional e restrições que apresentaram, respectivamente, potencial preditivo de 1,123 e 1,058. A rejeição da hipótese $\mathrm{H} 2$ evidencia que a estrutura da rede em determinados casos não afeta diretamente a cooperação entre as organizações em rede. Esse resultado se contrapõe à maioria dos estudos sobre capital social e redes organizacionais que defendem a relevância 
Tabela 2. Resultados do ajuste do modelo de mensuração e teste das hipóteses.

\begin{tabular}{|c|c|c|c|c|c|c|}
\hline \multicolumn{2}{|c|}{ Relações hipotetizadas } & \multirow{2}{*}{$\begin{array}{c}\begin{array}{c}\text { Coeficiente } \\
\text { de regressão } \\
\text { (Bootstrap) }\end{array} \\
0,530\end{array}$} & \multirow{2}{*}{$\begin{array}{c}\begin{array}{c}\text { Path } \\
\text { Coefficient } \\
(\boldsymbol{\beta})\end{array} \\
0,062\end{array}$} & \multirow{2}{*}{$\begin{array}{c}\begin{array}{r}\text { Razão } \\
\text { Crítica } \\
\text { (RC) }\end{array} \\
1,58\end{array}$} & \multirow{2}{*}{$\begin{array}{c}\begin{array}{c}\text { Potencial } \\
\text { explicativo }\end{array} \\
0,29\end{array}$} & \multirow{2}{*}{$\begin{array}{c}\begin{array}{r}\text { Teste de } \\
\text { hipótese }\end{array} \\
\begin{array}{c}\text { H1 } \\
\text { Rejeitada }\end{array}\end{array}$} \\
\hline $\begin{array}{l}\text { Estrutura } \\
\text { da rede }\end{array}$ & Confiança & & & & & \\
\hline $\begin{array}{l}\text { Ambiente } \\
\text { institucional }\end{array}$ & & & 0,102 & 1,71 & 0,46 & $\begin{array}{c}\mathrm{H} 3 \\
\text { Rejeitada }\end{array}$ \\
\hline Coordenação da rede & & & 0,200 & 6,84 & 0,99 & $\begin{array}{l}\text { H5 } \\
\text { Aceita }\end{array}$ \\
\hline Cooperação & & & 0,256 & 6,78 & 1,28 & $\begin{array}{l}\text { H7 } \\
\text { Aceita }\end{array}$ \\
\hline Restrições & & & $(-0,286)$ & $(-7,08)$ & 1,44 & $\begin{array}{l}\text { H14 } \\
\text { Aceita }\end{array}$ \\
\hline $\begin{array}{l}\text { Estrutura } \\
\text { da rede }\end{array}$ & Cooperação & 0,558 & 0,117 & 2,57 & 0,41 & $\begin{array}{c}\mathrm{H} 2 \\
\text { Rejeitada }\end{array}$ \\
\hline $\begin{array}{l}\text { Ambiente } \\
\text { institucional }\end{array}$ & & & 0,288 & 6,85 & 1,12 & $\begin{array}{c}\mathrm{H} 4 \\
\text { Aceita }\end{array}$ \\
\hline Coordenação da rede & & & 0,301 & 10,17 & 1,20 & $\begin{array}{c}\text { H6 } \\
\text { Aceita }\end{array}$ \\
\hline Restrições & & & $(-0,275)$ & $(-6,32)$ & 1,05 & $\begin{array}{l}\text { H15 } \\
\text { Aceita }\end{array}$ \\
\hline Cooperação & $\begin{array}{c}\text { Acesso a } \\
\text { informações }\end{array}$ & 0,396 & 0,355 & 7,53 & 0,95 & $\begin{array}{c}\mathrm{H} 8 \\
\text { Aceita }\end{array}$ \\
\hline Confiança & & & 0,333 & 5,82 & 1,03 & $\begin{array}{l}\text { H9 } \\
\text { Aceita }\end{array}$ \\
\hline Confiança & $\begin{array}{c}\text { Acesso ao } \\
\text { conhecimento }\end{array}$ & 0,477 & 0,219 & 7,89 & 0,806 & $\begin{array}{l}\text { H10 } \\
\text { Aceita }\end{array}$ \\
\hline Cooperação & e inovações & & 0,305 & 9,03 & 1,12 & $\begin{array}{l}\text { H13 } \\
\text { Aceita }\end{array}$ \\
\hline $\begin{array}{l}\text { Acesso a } \\
\text { informações }\end{array}$ & & & 0,278 & 7,89 & 1,04 & $\begin{array}{l}\text { H16 } \\
\text { Aceita }\end{array}$ \\
\hline Cooperação & $\begin{array}{c}\text { Inserção } \\
\text { mercadológica }\end{array}$ & 0,587 & 0,245 & 11,20 & 1,07 & $\begin{array}{l}\text { H11 } \\
\text { Aceita }\end{array}$ \\
\hline Confiança & & & 0,223 & 9,87 & 1,06 & $\begin{array}{l}\mathrm{H} 12 \\
\text { Aceita }\end{array}$ \\
\hline $\begin{array}{l}\text { Acesso a } \\
\text { conhecimentos }\end{array}$ & & & 0,240 & 9,28 & 0,97 & $\begin{array}{l}\text { H17 } \\
\text { Aceita }\end{array}$ \\
\hline Restrições & & & $(-0,204)$ & $(-6,85)$ & 1,069 & $\begin{array}{c}\text { H18 } \\
\text { Aceita }\end{array}$ \\
\hline
\end{tabular}

dos laços e do posicionamento dos atores para a construção de ações cooperativas (Batjargal, 2003; Sorama, et al., 2004).

Em relação aos construtos preditivos do construto acesso a informações, constatou-se que 39,6\% da variância do construto acesso a informações foram explicados pelas relações de confiança e pela cooperação entre as empresas. A análise dos Path Coefficients confirma as hipóteses $\mathrm{H} 8$ e H9 e indica que o construto cooperação tem impacto de 0,355 sobre acesso a informações, enquanto o construto confiança apresentou impacto de 0,333. Esses resultados indicam que a cooperação e a confiança estabelecidas contribuem para o acesso a informações, reforçando a tese de que o capital social derivado das relações em rede contribui para a redução das incertezas e o aumento das trocas de informações e de conhecimento entre os parceiros (Agndal et al., 2008).

Constatou-se que $47,7 \%$ da variância do construto acesso ao conhecimento e inovação foram explicados pelos construtos cooperação, confiança e acesso a informações, ou seja, verificou-se que estes construtos estão associados e impactaram positivamente o acesso ao conhecimento estabelecido entre as empresas integrantes da rede. A análise dos coeficientes de caminho $(\beta)$ evidencia que as hipóteses H10, H13 e H16 podem ser confirmadas, tendo os três constructos apresentado potencial explicativo acima 
do recomendado, que é de 0,80 . Essas evidências reforçam a tese de que o acesso ao conhecimento e a inovações depende da cooperação e da confiança.

Sob a ótica da sociologia econômica (Rothstein \& Stolle, 2008; Uslaner, 2008), as relações de confiança, cooperação e reciprocidade são comportamentos mediadores das relações nas redes organizacionais e de melhoria da sua eficiência. Esses comportamentos reduzem os riscos relativos às relações de troca, contribuem para a melhoria do processo de comunicação e promovem o acesso a novas tecnologias e conhecimentos.

Verificou-se, ainda, que os construtos restrições, cooperação, confiança e acesso ao conhecimento são preditivos da inserção mercadológica, ou seja, constatou-se que $58,7 \%$ da variância da inserção mercadológica foram explicados por esses quatro construtos. Destaca-se ainda que os construtos cooperação, confiança e acesso ao conhecimento estão associados, e impactam positivamente, à inserção mercadológica das empresas. $\mathrm{O}$ construto restrições, por sua vez, impactou negativamente o referido construto. Observa-se que o construto restrições impactou negativamente $(-0,204)$ a inserção mercadológica das empresas integrantes da rede e o construto cooperação foi o que apresentou o maior impacto positivo, com valor de 0,245. Os construtos acesso ao conhecimento e confiança impactaram positivamente a inserção mercadológica em, respectivamente, 0,240 e 0,223 . Verificou-se também que os construtos explicativos da inserção mercadológica apresentam potenciais explicativos acima de 0,80 . Portanto, confirmam-se as hipóteses H11, H12, H17 e H18.

A confirmação das hipóteses subjacentes à equação estrutural da inserção mercadológica indica a sua dependência em relação à confiança, à cooperação e à troca de informações entre as empresas de Santa Rita do Sapucaí. Essas evidências encontram sustentação nas reflexões de Agndal et al. (2008), Chetty \& Agndala (2007) e Lin (1999). Para estes autores, as dimensões relacionais do capital social exercem forte influência na melhoria do desempenho, na troca de informações e de conhecimentos, no compartilhamento de recursos estratégicos, na inovação e na inserção mercadológica das organizações que atuam em rede.
Em outros termos, para os autores, o capital social derivado das relações interorganizacionais deve ser visto como um mecanismo de mediação que contribui para a redução das incertezas e o aumento das trocas de informações e de conhecimento entre os parceiros.

Uma vez verificado o ajuste das equações estruturais para cada um dos constructos exógenos, passa-se a avaliar a qualidade do modelo explicativo hipotetizado (Tabela 3). Para tanto, foram empregados os índices de qualidade do ajuste (GOF-bootstrap), a análise da variância explicada e outras estatísticas. A análise das estatísticas apresentadas na Tabela 3 confirma a qualidade do ajuste geral do modelo explicativo do capital social.

O índice de ajuste relativo foi de 0,826 , situando-se entre o limite inferior $(0,753)$ e o limite superior $(0,887)$, a $95 \%$ de confiança e razão crítica de 26,12. Essas estatísticas evidenciam que os valores de GoF-Bootstrap estão próximos de 1, indicando que o modelo que apresenta alto potencial explicativo do capital social presente na rede interorganizacional estudada (Hair et al., 2005; Falk \& Miller, 1992).

Outros procedimentos derivados da aplicação do método PLS também reforçam a validade estrutural do modelo explicativo das relações entre as dimensões (estruturais, relacionais, benefícios e restrições) do capital social construído pelas empresas integrantes da rede. A análise da variância explicada também reforça esta particularidade do modelo explicativo (Tabela 4). Para Lohmöller (1989) e Maestro (2004), quanto menor for a variância não explicada pelos construtos latentes, melhor o ajuste do modelo estrutural. A variância não explicada do modelo estrutural foi de 0,517 , ou seja, (1 - média da variância explicada).

O modelo estrutural também apresenta validade discriminante, evidenciada pela variância média explicada (AVE), cujo valor encontrado $(0,582)$ foi maior que o valor de referência 0,50 . Pôde-se observar, pelos dados da Tabela 4, também, que todos os construtos latentes estimados apresentaram validade discriminante acima do valor de referência $(0,5)$ sugerido pela literatura (Hair et al., 2005; Falk \& Miller, 1992). Em síntese, as análises apresentadas neste tópico evidenciaram o ajuste dos modelos de mensuração e estrutural, bem como o ajuste geral do modelo explicativo do capital social.

Tabela 3. Qualidade do ajuste geral do modelo.

\begin{tabular}{lcccccc}
\hline & GoF & GoF Bootstrap & Erro padrão & $\begin{array}{c}\text { Razão crítica } \\
(\mathbf{C R})\end{array}$ & $\begin{array}{c}\text { Limite } \\
\text { inferior } \\
(\mathbf{9 5 \% )}\end{array}$ & $\begin{array}{c}\text { Limite } \\
\text { superior } \\
\mathbf{( 9 5 \% )}\end{array}$ \\
\hline Absoluto & 0,530 & 0,544 & 0,043 & 12,399 & 0,456 & 0,631 \\
Relativo & 0,874 & 0,826 & 0,033 & 26,120 & 0,753 & 0,887 \\
Modelo externo & 0,991 & 0,984 & 0,007 & 148,920 & 0,958 & 0,990 \\
Modelo interno & 0,882 & 0,839 & 0,032 & 27,813 & 0,768 & 0,898 \\
\hline
\end{tabular}


Tabela 4. Indicadores do ajuste geral do modelo explicativo.

\begin{tabular}{|c|c|c|c|c|c|}
\hline Variável latente & Tipo & $\mathbf{R}^{2}$ & $\mathbf{R}^{2}$ ajustado & $\begin{array}{c}\text { Média } \\
\text { comunalidades } \\
\text { (AVE) }\end{array}$ & Rho de D.G. \\
\hline Estrutura da rede & Exógena & & & 0,675 & \\
\hline Ambiente institucional & Exógena & & & 0,568 & 0,840 \\
\hline Coordenação & Exógena & & & 0,779 & 0,914 \\
\hline Restrições & Exógena & & & 0,551 & 0,824 \\
\hline Cooperação & Endógena & 0,521 & 0,502 & 0,505 & 0,796 \\
\hline Confiança & Endógena & 0,508 & 0,482 & 0,575 & 0,871 \\
\hline Acesso a informações & Endógena & 0,377 & 0,369 & 0,645 & 0,845 \\
\hline Acesso ao conhecimento & Endógena & 0,447 & 0,433 & 0,500 & 0,798 \\
\hline Inserção mercadológica & Endógena & 0,560 & 0,543 & 0,528 & 0,817 \\
\hline Média & & 0,483 & & 0,582 & \\
\hline
\end{tabular}

\section{Considerações finais}

As análises dos resultados obtidos a partir da aplicação da modelagem de equações estruturais evidenciaram que o modelo explicativo proposto tem validade nomológica e estrutural. Portanto, pode-se afirmar que o capital social inerente à rede de empresas estudada é constituído por três dimensões cujas inter-relações foram evidenciadas neste artigo, ou seja, a dimensão estrutural (estrutura, coordenação da rede e o ambiente institucional em que ela está inserida); a dimensão relacional (confiança e cooperação); e a terceira dimensão, que envolve os benefícios (acesso a novos conhecimentos e informações e a inserção mercadológica decorrente da participação na rede) e as restrições à formação do capital social (comportamento oportunista das empresas).

A validação do modelo explicativo proposto envolveu a verificação de 18 hipóteses, das quais três não se confirmaram, por apresentarem baixo potencial explicativo ou significância estatística. Entre as hipóteses rejeitadas estão aquelas que mensuravam as relações de causa e efeito entre a estrutura da rede e os aspectos relacionais do capital social, ou seja, as relações de confiança e cooperação. Em outros termos, os laços, a proximidade e a posição das empresas na rede não afetam de forma significativa as relações de confiança e cooperação entre elas. Essa evidência se contrapõe à maioria de estudos que destacam a relevância da estrutura social da rede para a construção da cooperação e da confiança em redes organizacionais. Por um lado, este resultado pode ser explicado, em parte, pelo baixo grau de proximidade e pela fragilidade dos laços estabelecidos entre as empresas constitutivas da rede organizacional em foco. Por outro, essa baixa coesão empresarial também sinaliza a necessidade de se intensificar os esforços de cooperação e de consolidação da confiança entre as referidas empresas inseridas em um mesmo ambiente institucional. A natureza deste contexto e a atuação do poder local são apontadas, pela teoria, como sendo elementos determinantes para a construção das relações de confiança entre as empresas, consequentemente para a formação do capital social. Esta relação de causa e efeito não se confirmou, indicando que a confiança entre as empresas não sofre efeitos positivos do contexto institucional e da ação do poder local. Pode-se concluir que a confiança entre as empresas não depende da ação do poder público, tendo elas sofrido pouca influência do ambiente institucional.

As análises dos resultados da pesquisa sinalizaram também que a confiança construída entre as empresas integrantes da rede está associada e impacta positivamente a cooperação entre as empresas. Embora a confiança e a cooperação sejam fenômenos sociais distintos, eles mantêm forte imbricação entre si. Assim, as relações de cooperação e o nível de confiança estabelecido entre as empresas integrantes da rede organizacional estudada têm contribuído para a produção de diferentes benefícios diretos e indiretos. Entre os benefícios do capital social verificados pela pesquisa destacam-se o acesso a informações, a ampliação da inserção no mercado e a obtenção de novos conhecimentos. Entre os indiretos, identificados a partir da análise dos resultados da fase exploratória da pesquisa, destacam-se: o uso compartilhado de laboratórios de pesquisa entre instituições de ensino e empresas; a qualificação técnico-profissional de pessoas; desenvolvimento conjunto de ações cooperativas, a exemplo de compras coletivas e rodadas de negócios nacionais e internacionais, e a construção de uma cultura local que tem fortalecido a confiança e cooperação entre as empresas integrantes da rede empresarial estudada. A despeito dessas evidências, a formação do capital social na rede de empresas estudadas tem encontrado algumas barreiras, ou seja, a cooperação e a confiança foram impactadas de forma negativa por alguns elementos restritivos à formação do capital 
social. Dentre estas restrições se destacaram aquelas relativas à transferência de conhecimentos tecnológicos inovadores; a necessidade de observação, controle e formalização de relações entre os parceiros e a presença de ações individualistas que podem produzir riscos à formação do capital social. Esta constatação sinaliza para a necessidade de realização de novos estudos que sejam capazes de evidenciar os riscos relacionados aos efeitos negativos do capital social, cuja gênese pode estar atrelada à desconfiança, aos conflitos de interesses e à lógica de ação oportunista, os quais podem permear as relações entre organizações que atuam em rede.

Espera-se que os resultados tenham contribuído para a ampliação do conhecimento sobre o tema capital social, pois a proposta teórico-metodológica em tela poderá ser replicada por outros pesquisadores que estejam interessados em estudar o referido tema em outros tipos de redes organizacionais. As evidências encontradas poderão estimular a definição de ações coletivas que fortaleçam as relações de cooperação e confiança, de modo a preservar o capital social construído na rede estudada. Além disso, destaca-se que a realização da pesquisa que deu origem a este artigo exigiu a superação de diversas limitações, mas outras permaneceram, a exemplo da dificuldade de mensurar de forma indireta os construtos constitutivos do capital social. A formulação de qualquer modelo explicativo implica a escolha parcimoniosa de alguns conceitos em detrimento de outros. Ressalta-se também que muitos aspectos da realidade estudada não foram abordados. Portanto, a generalização de resultados requer uma postura reflexiva e cuidadosa, que evite extrapolações acríticas das análises desenvolvidas ao longo deste texto acadêmico. Por fim, sugere-se a condução de pesquisas históricas de caráter longitudinal, que incorporem as dimensões política e simbólica inerentes à formação de capital social, discutam o papel do Estado e de seus agentes na geração do capital social e investiguem o processo de institucionalização da confiança e cooperação nesse tipo de arranjo em redes organizacionais.

\section{Agradecimentos}

Os autores agradecem ao CNPq, à FAPEMIG e à CAPES o financiamento da pesquisa e a concessão de bolsas de pós-graduação aos discentes participantes do projeto que deu origem a este trabalho.

\section{Referências}

Adler, P. S., \& Kwon, S. (2002). Social capital: prospects for new concept. Academy of Management Review, 27(1), 17-40.

Agndal, H., Chetty, S., \& Wilson, H. (2008). Social capital dynamics and foreign market entry. International Business
Review, 17(6), 663-675. http://dx.doi.org/10.1016/j. ibusrev.2008.09.006.

Ahlerup, P., Olsson, O., \& Yanagizawa, D. (2009). Social capital versus institutions in the growth process. European Journal of Political Economy, 25(1), 1-14. http://dx.doi. org/10.1016/j.ejpoleco.2008.09.008.

Amato, S., Esposito Vinzi, V., \& Tenenhaus, M. (2004). A global goodness-of-fit index for PLS structural equation modeling. Oral Communication to PLS Club, 24, 1-4.

Anand, B. N., \& Khanna, T. (2000). Do firms learn to create value? The case of alliances. Strategic Management Journal, 21(3), 295-315. http://dx.doi.org/10.1002/(SICI)10970266(200003)21:3<295::AID-SMJ91>3.0.CO;2-O.

Anand, V., Glick, W., \& Manz, C. (2002). Capital social: explorando a rede de relações da empresa. Revista de Administração de Empresas, 42(4), 57-71.

Associaçâo Brasileira da Indústria Elétrica e Eletrônica ABINEE. (2009). Panorama econômico e desempenho setorial. São Paulo: ABINEE.

Batjargal, B. (2003). Social capital and entrepreneurial performance in Russia: a longitudinal study. Organization Studies, 24(4), 535-556. http://dx.doi.org/10.1177/017 0840603024004002.

Batt, P. J. (2008). Building social capital in networks. Industrial Marketing Management, 37(5), 487-491. http://dx.doi.org/10.1016/j.indmarman.2008.04.002.

Björk, P., \& Virtanen, H. (2005). What tourism project managers need to know about co-operation facilitators. Scandinavian Journal of Hospitality and Tourism, 5(3), 212-230. http://dx.doi.org/10.1080/15022250510014354.

Bjørnskov, C. (2006). The multiple facets of social capital. European Journal of Political Economy, 22(1), 22-40. http://dx.doi.org/10.1016/j.ejpoleco.2005.05.006.

Borgatti, S. P., \& Cross, R. (2003). A relational view of information seeking and learning in social networks. Management Science, 49(4), 432-445. http://dx.doi. org/10.1287/mnsc.49.4.432.14428.

Borgatti, S. P., \& Foster, P. C. (2003). The network paradigm in organizational research: a review and tipology. Journal of Management, 29(6), 991-1013. http://dx.doi. org/10.1016/S0149-2063(03)00087-4.

Bourdieu, P. (1979). Les trois états du capital culturel. Actes de la Recherche en Sciences Sociales, 30(1), 3-6. http://dx.doi.org/10.3406/arss.1979.2654.

Brunie, A. (2009). Meaningful distinctions within a concept: relational, collective, and generalized social capital. Social Science Research, 38(2), 251-265. http://dx.doi. org/10.1016/j.ssresearch.2009.01.005. PMid:19827175

Burt, R. S. (2001). Structural holes versus network closure as social capital. In N. Lin, K. S. Cook, \& R. S. Burt. (Eds.), Social capital: theory and research (Cap. 2, pp. 31-56). New York: Aldine de Gruyter.

Cassiolato, J. E., \& Lastres, M. H. (2003). O foco em arranjos produtivos e inovativos locais de micro e pequenas empresas. In J. E. Cassiolato, H. M. M. Lastres \& M. L. Maciel (Orgs.), Pequenas empresas: cooperação e desenvolvimento local. Rio de Janeiro: Relume Dumará.

Chetty, S., \& Agndala, H. (2007). Social capital an its influence in internacionalization mode among SMEs. Journal of International Marketing, 15(1), 1-29. 
Chin, W. W. (1998). The partial least squares approach for structural equation modeling. In G. A. Marcoulides (Ed.), Modern methods for business research (pp. 295-336). Mahwah: Lawrence Erlbaum Associates.

Chow, W. S., \& Chan, L. S. (2008). Social network, social trust and shared goals in organizational knowledge sharing. Information \& Management, 45(7), 458-465. http://dx.doi.org/10.1016/j.im.2008.06.007.

Coleman, J. S. (1988). Social capital in the creation of human capital. American Journal of Sociology, 94(Supl.), S95-S120. http://dx.doi.org/10.1086/228943.

Coser, C. (2003). Relações interorganizacionais e estruturas institucionais: um estudo no espaço social de Videira (Dissertação de mestrado). Centro de Pesquisa e Pós-Graduação em Administração, Universidade Federal do Paraná, Curitiba.

De Wever, S., Martens, R., \& Vandenbempt, K. (2005). The impacto f trust on strategic resources acquisition through interorganizational networks: towards a conceptual model. Human Relations, 58(12), 1523-1543. http:// dx.doi.org/10.1177/0018726705061316.

Dias, M. C. (2007). Antecedentes do impacto da tecnologia de informação na cadeia de suprimentos e efeitos desse impacto na performance de cooperativas agroindustriais (Tese de doutorado). Universidade de São Paulo, São Paulo.

Durston, J. (2002). El capital social campesino en la gestión del desarrollo rural: díadas, equipos, puentes y escaleras. Chile: Comisión Económica para América Latina y el Caribe.

Falk, R. F., \& Miller, N. B. (1992). A primer for soft modeling. Akron: University of Akron Press.

Fidrmuc, J., \& Gerxhani, K. (2008). Mind the gap! Social capital, East and West. Journal of Comparative Economics, 36(2), 264-286.

Furlanetto, L. E. (2008). Instituições e desenvolvimento econômico: a importância do capital social. Revista Sociologia e Política, 16(Supl.), 55-67.

Galunic, C., \& Moran, P. (2000). Social capital and productive exchange: structural and relational embeddedness and managerial performance link (INSEAD Working Paper, 2000/07/OB). Fontainebleau: INSEAD.

Goel, S., Bell, G. G., \& Pierce, J. L. (2005). The perils of Pollyanna: development of the over-trust construct. Journal of Business Ethics, 58(1-3), 203-218. http:// dx.doi.org/10.1007/s10551-005-1415-6.

Granovetter, M. (1973). The strength of weak ties. American Journal of Sociology, 78(6), 1360-1380. http://dx.doi. org/10.1086/225469.

Granovetter, M. (1985). Economic action and social structure: the problem of embeddedness. American Journal of Sociology, 91(3), 481-510. http://dx.doi. org/10.1086/228311.

Granovetter, M. (1990). The old and new economic sociology: a history and an agenda. In R. Friedland \& A. F. Robertson (Eds.), Beyond the marketplace: rethinking economy and society. New York: Aldine de Gruyter.

Granovetter, M. S. (1994). Business groups. In N. Smelser \& R. Swedberg (Eds.), Handbook of economic sociology (pp. 453-475). Princeton: Princeton University Press/ Russel Sage Foundation.
Granovetter, M., \& Swedberg, R. (1992). The sociology of economic life. Boulder: Westview Press.

Gulati, R., \& Nickerson, J. A. (2008). Interorganizational trust, governance choice, and exchange performance. Organization Science, 19(5), 668-708. http://dx.doi. org/10.1287/orsc.1070.0345.

Hair, J. F., Jr., Anderson, R. E., Tatham, R. L., \& Black, W. C. (2005). Análise multivariada de dados (A. S. Sant'anna \& A. Chaves No., Trad., 5 ed.). Porto Alegre: Bookman. 593 p.

Houghton, S. M., Smith, A. D., \& Hood, J. N. (2009). The influence of social capital on strategic choice: an examination of the effects of external and internal network relationships on strategic complexity. Journal of Business Research, 62(12), 1255-1261. http://dx.doi. org/10.1016/j.jbusres.2009.01.002.

Kaasa, A. (2009). Effects of different dimensions of social capital on innovative activity: evidence from Europe at the regional level. Technovation, 29(3), 218-233. http://dx.doi.org/10.1016/j.technovation.2008.01.003.

Koka, B., \& Prescott, J. (2002). Strategic alliances as social capital: a multidimensional view. Strategic Management Journal, 23(9), 795-816. http://dx.doi. org/10.1002/smj.252.

Leana, C. R., \& Pil, F. K. (2006). Social capital and organizational performance: evidence from urbam public schools. Organization Science, 17(3), 353-366. http://dx.doi.org/10.1287/orsc.1060.0191.

Leana, C. R., \& Van Buren, H. J. (1999). Organizational social capital and employment practices. Academy of Management Review, 24(3), 538-555.

Lima, D. O., Fo., Maia, F. S., Sproesser, R. L., Moraes, F., \& Moraes, R. (2006). Redes de cooperação no varejo alimentar de vizinhança: percepções dos associados. Gestão \& Produção, 13(2), 311-324.

Lin, N. (1999). Building a network theory of social capital. Connections, 22(1), 28-51.

Lin, N. (2008). A network theory of social capital. In D. Castiglione, J. Van Deth \& G. Wolleb (Eds.), The handbook of social capital (pp. 50-69). Oxford: Oxford University Press.

Lohmöller, J. B. (1989). Latent variable path modeling with partial least squares. New York: Springer-Verlag.

Lyons, B., \& Mehta, J. (1997). Contracts, opportunism and trust: self-interest and social orientation. Cambridge Journal of Economics, 21(2), 239-257.

Machado-da-Silva, C. L., \& Coser, C. (2006). Rede de relações interorganizacionais no campo organizacional de Videira-SC. Revista de Administração Comtemporânea, 10(4), 9-45.

Maestro, A. D., Fo. (2004). Modelo relacional entre modernização organizacional, práticas inovadoras de treinamento e satisfação no trabalho (Tese de doutorado). Universidade Federal de Minas Gerais, Belo Horizonte.

Marconi, M. A., \& Lakatos, E. M. (2003). Fundamentos de metodologia científica (5 ed.). São Paulo: Atlas. 134 p.

Molina, J. L. (2001). El análisis de redes sociales: una introducción. Barcelona: Edicions Bellaterra.

Muls, L. M. (2008). Desenvolvimento local, espaço e território: o conceito de capital social e a importância 
da formação de redes entre organismos e instituições locais. Revista Economia, 9(1), 1-21.

Nahapiet, J., \& Ghoshal, S. (1998). Social capital, intellectual capital, and the organizational advantage. Academy of Management Review, 23(2), 242-266.

Netemeyer, R. G., Bearden, W. O., \& Sharma, S. (2003). Scaling procedures: issues and applications. Thousand Oaks: Sage Publications.

O'Cass, A., \& Grace, D. (2008). Understanding the role of retail store service in light of self-image-store image congruence. Psychology and Marketing, 25(6), 521-537. http://dx.doi.org/10.1002/mar.20223.

Oliver, A. L. (2001). Strategic alliances and the learning lifecycle of biotechnology firms. Organization Studies, 22(3), 467-489. http://dx.doi.org/10.1177/0170840601223004.

Onyeiwu, S., \& Jones, R. R. (2003). Institutionalist perception of cooperative behavior. Journal of SocioEconomics, 32(3), 233-248. http://dx.doi.org/10.1016/ S1053-5357(03)00037-4.

Pesämaa, O., \& Hair, J. F., Jr. (2007). More than friendship is required: An empirical test of cooperative firm strategies. Management Decision, 45(3), 602-615. http://dx.doi. org/10.1108/00251740710745142.

Pesämaa, O., Örtqvist, D., \& Hair, J. F., Jr. (2007). It's all about trust and loyalty: Partner selection mechanisms in tourism networks. World Journal of Tourism Small Business Management, 1, 55-61.

Portes, A. (1998). Social Capital: its origins and aplications in contemporary sociology. Annual Review of Sociology, 24(1), 1-24. http://dx.doi.org/10.1146/annurev.soc.24.1.1.

Provan, K. G., Fish, A., \& Sydow, J. (2007). Interoganizational networks at network at the level: a review of empirical literature on whole networks. Journal of Management, 33(3), 479-516. http://dx.doi.org/10.1177/0149206307302554.

Putnam, R. D. (2000). Bowling alone: collapse and revival of american community. New York: Simon and Schuster.

Rothstein, B., \& Stolle, D. (2008). Political institutions and generalized trust. In D. Castiglione, J. Van Deth \& G. Wolleb (Eds.), The handbook of social capital (pp. 273-302). Oxford: Oxford University Press.

Sabatini, F. (2008). Social capital and the quality of economic development. Kyklos, 61(3), 466-499. http://dx.doi. org/10.1111/j.1467-6435.2008.00413.x.

Smith, D. A., \& Lohrke, F. T. (2008). Entrepreneurial network development: trusting in the process. Journal of Business Research, 61(4), 315-322. http://dx.doi. org/10.1016/j.jbusres.2007.06.018.

Sorama, K., Katajamaki, A., \& Varamaki, E. (2004). Cooperation between SMES: social capital and learning perspective. Procedings of the $13^{\circ}$ Conference on Small Bussiness Research, 1(2), 1-15.
Stuart, T. E. (2000). Interorganizational alliances and the performance of firms: A study of growth and innovation. Strategic Management Journal, 21(8), 791-811. http:// dx.doi.org/10.1002/1097-0266(200008)21:8<791::AIDSMJ121>3.0.CO;2-K.

Tenennhaus, M., \& Hanafi, M. (2007). A bridge between PLS path modeling and multi-block data analysis. In E. Vinzi, W. Chin, J. Henseler \& H. Wang (Eds.), Handbook of partial least squares (PLS): concepts, methods and applications (Vol. 2, pp. 47-82). Berlin: Springer-Verlag.

Tenennhaus, M., Vinzi, V. E., Chatelin, Y. M., \& Lauro, C. (2005). PLS path modeling. Computational Statistics \& Data Analysis, 48(1), 159-205. http://dx.doi.org/10.1016/j. csda.2004.03.005.

Theingi, Purchase, S., \& Phungphol, Y. (2008). Social capital in southeast asian business relationships. Industrial Marketing Management, 37(5), 523-530. http://dx.doi. org/10.1016/j.indmarman.2007.09.014.

Tsai, W., \& Ghoshal, S. (1998). Social capital and value creation: the role of intrafirm networks. Academy of Management Journal, 41(4), 464-476. http://dx.doi. org/10.2307/257085.

Uslaner, E. (2008). Trust as a moral value. In D. Castiglione, J. Van Deth \& G. Wolleb (Eds.), The handbook of social capital (pp. 101-121). Oxford: Oxford University Press.

Vale, G. M. V., Amâncio, R., \& Lauria, M. C. (2006). Capital social e suas implicações para o estudo das organizações. Revista Organizações \& Sociedade, 13(36), 45-63. http://dx.doi.org/10.1590/S1984-92302006000100003.

Vidal, A. C. (2004). Building social capital to promote community equity. Journal of the American Planning Association, 70(2), 164-168.

Wasserman, S., \& Faust, K. (1994). Social network analysis: methods and applications. New York: Cambridge University Press.

Wíden-Wulff, G., \& Ginman, M. (2004). Explaining knowledge sharing in organizations through the dimensions of social capital. Journal of Information Science, 30(5), 448-458. http://dx.doi.org/10.1177/0165551504046997.

Wold, H. (1985). Partial least squares. In S. Kotz \& N. L. Johnson (Eds.), Encyclopedia of statistical sciences (Vol. 6, pp. 581-591). New York: John Wiley \& Sons.

Wold, S. (1995). PLS for multivariate linear modelling. In H. van de Waterbeemd (Ed.), QSAR: chemometric methods in molecular design (Vol. 2, pp. 195-218). Weinheim: Wiley-VCH.

XLSTAT. (2009). XLSTAT-PLSPM module. XLSTAT software. Paris: Addinsoft. 